\title{
Pearls and Pitfalls of HIV-1 Serologic Laboratory Testing
}

\author{
Jiasheng Shao', Yunzhi Zhang1, Yi-Wei Tang2 and Hongzhou Lu1 \\ ${ }^{1}$ Department of Infectious Diseases ${ }^{1}$, Shanghai Public Health Clinical Center, \\ Fudan University, Shanghai \\ ${ }^{2}$ Departments of Pathology and Medicine, \\ Vanderbilt University Medical Center, Nashville, \\ 'People's Republic of China \\ ${ }^{2} \mathrm{TN}, U S A^{2}$
}

\section{Introduction}

\subsection{Case 1}

A 45-year-old single man presents to a primary care unit with complaints of 'having a prostate problem". He wants to find out whether he has the same condition because his father and elder brother have the same problem. He tells doctors that he has always been in good health except for urinary symptoms. Approximately 1 year ago, he paid a medical visit due to a sore throat. When the patient is asked more closely about other symptoms besides the sore throat, he said that skin rash, coughs, malaise are included. He was prescribed a course of antibiotics and spent a week at home before returned to work. However, it took almost 2 weeks to recover fully. The patient accepts routine HIV testing and other tests specific for STIs are also obtained on the basis of his history. The patient is tested with the standard blood test. He is told that the HIV test results are negative when he returns for follow-up 2 weeks later. He comments that after being made aware of his personal risks, he convinced his wife to be tested (who is negative); because they both had other sex partners with an unknown sex and drug use history during their separation. Although family members and alleged partners, including spouses, should not be notified of a specific person's tests result, the CDC recommends as part of partner services that they should be independently encouraged to have HIV testing as part of routine care (CDC, 2008).

\subsection{Case 2}

A 21-year-old man comes to the outpatient clinic with complaints of 'burning while urinating' for the past 3 days. Symptoms such as fevers, flank pain, or penile discharge have been denied. He had several sexual partners over the past 6 months. He uses condoms with his casual partners but prefers not to do so with his primary partner. He attributes his present symptoms to condom breakage during sexual intercourse with a casual partner. He tells that he has sex only with men, but denies use of injection drugs. He has never been tested for HIV. Reasons for previously declining are that he 'is usually careful' and, besides, 'Magic Johnson has it and he looks good.' After some discussion, the patient states that he 
has had blood drawn at emergency department visits at other hospitals in the past several years. However, he did not return for the test results and assumed that because he was not contacted about the results, all tests, including any for HIV, must be negative. However, he states that he is unemployed and frequently stays with friends at different locations. The patient initially declines HIV screening. He has a family member who works at the local health department and is very concerned that this person would have access to his results if he tested positive. State laws require that positive confirmatory HIV test results be reported to the surveillance division of the respective health department. However, access to test results is restricted to a very few individuals who have signed confidentiality agreements. Additionally, as noted after being reassured about test confidentiality, the patient agrees to screening. His rapid HIV test is reactive. This result was confirmed by follow-up testing. Linkage of patients newly diagnosed HIV positive to further care is very important and relatively brief interventions can be effective (Craw, JA., et al., 2008).

On the basis of other laboratory indices, such as CD4 count and viral load, it appears that the patient has been infected for many years.

\subsection{Case 3}

A 16-month-old boy presented with prolonged fever and oral candidiasis for the past 6 month. He was a term infant delivered by cesarean section without complications. He was breast-fed for the first 6 days of life and then switched to bottle-feeding. At one month of age, he developed oral candidiasis and was treated with mycostatin, but no effect was observed. Subsequently, he was hospitalized due to prolonged fever and cough and diagnosed with Pseudomonas aeruginosa infection by sputum culture. His cytomegalovirus and adenovirus IgM antibody tests were positive. Ultrasound examination of the abdomen revealed hepatosplenomegaly. His mother was HIV antibody positive one week before delivery, which was subsequently confirmed by a Genetic System HIV-1 Western-blot. Her CD4+ cell count was $212 / \mathrm{mm}^{3}$ and viral load was $1.6 \times 10^{6}$ copies $/ \mathrm{ml}$. The boy had a rapid HIV-1/2 antibody test performed twice in serum at age 5- and 7-month, which were negative. The Abbott rapid test was repeated at age 7 - and 8-month during his hospitalization and the results remained negative; however, HIV-1/2 antibody was detected in his serum by an enzyme-linked immunosorbent assay (TNA-Abb, Dainabot Co., Tokyo, Japan) at the time of readmission when he was 7-mo old. HIV-1 Western-blot was performed in plasma at the Shanghai Centers for Disease Control and prevention, which revealed the presence of a single HIV gp120 band. His HIV viral loads ranged from 1.5 to $2.2 \times 105$ copies / $\mathrm{ml}$ in plasma during his hospitalization (Zhang, YZ., et al., 2008).

\subsection{Case 4}

A 26-year-old woman presents to a community-based facility because she suspects that she is pregnant. She has not had a menstrual period for 2 months. She has been married for 5 years, but has no child. The pregnant test is positive. The patient has a family history of sickle cell disease, and she asks about the diseases that she and her unborn child will be screened for as part of the initial prenatal evaluation. The patient was informed of the various screening tests routinely included in the initial prenatal evaluation. Although an HIV test is included in the general consent for obstetric care, she declines. She remarks that she has been monogamous for 5 years and had a negative test 'back then.' She reports having had some marital difficulties 'like all couples,' but she is not concerned about 
contracting HIV because she 'has never used drugs and is not gay.' Besides, her husband 'would kill me if I ever gave him something'. After the patient spent time discussing her reasons for declining testing and these concerns were addressed by the provider, she realized that she was not being singled out for an HIV test and agreed to screening. The result of the rapid HIV test was negative. She breathes a sigh of relief and discloses that some of her marital problems were due to her husband's infidelity.

\section{Discussion and comments}

It is estimated currently that $21 \%$ of HIV cases in the United States are undiagnosed (Campsmith, ML., et al., 2010). Recent studies showed that missed opportunity visits, i.e., when HIV screening is not included as a routine part of the appraisal or is not offered when it should have been, are very common

(Althoff, KN., et al., 2010; Duffus, WA., et al., 2009). In addition, there will always be a new generation of individuals at risk for HIV acquisition. Screening should be offered regardless of perceived behavioral risk, and the opportunity should not be lost to educate those who test negative. To redirect local health jurisdictions in taking a broader approach to HIV testing in their communities, the CDC published revised recommendations for routine HIV testing in healthcare settings in 2006 (Branson, BM., et al., 2006). These recommendations include routine screening of 13- to 64-year-old patients. However, it may be prudent to screen beyond the recommended older age limit if history suggests continued sexual activity. All patients being screened should be asked about specific behaviors associated with increased risk such as sexual practices, including multiple partners, condom use, and use of performance-enhancing medications and about injection drug use (Adimora, AA., et al., 2003). The CDC further recommends that routine screening take place in all healthcare facilities and institutions, unless prevalence of undiagnosed HIV infection in the patient population has been documented to be $<0.1 \%$. If such data are unavailable, routine screening should occur until it has been prospectively established that diagnostic yield is $<1$ per 1000 patients screened. When a yield of $<1$ per 1000 is present, routine screening is no longer warranted and targeted testing should be used. Other recommendations for routine screening include any patient initiating treatment for tuberculosis (Taylor, Z., et al. 2005), because of the increased incidence of coinfection and the requisite modification to HIV therapy in case of coinfection in developing countries (Jiang, XY., et al., 2008). Any patient seeking treatment for an STD should be screened at each visit for a new complaint. Testing should be performed whether the patient is known or suspected to have specific behavioral risks for HIV infection. Repeat screening of persons not likely to be at high risk for HIV should be based on clinical judgment. Individuals at high risk for HIV should be screened at least annually. Indications of high risk include (1) injection drug users and their sex partners, (2) persons who exchange sex for drugs or money, (3) sex partners of HIV-infected individuals, (4) men who have sex with men (MSM), (5) heterosexuals who themselves or whose sex partners have had more than 1 sex partner since their most recent HIV test. Any identified risk exposure within the past 3-6 months should prompt rescreening within the next 3-6 months. If risk behavior continues, periodic testing in 3-6 months is recommended.

A meta-analysis of 11 independent findings (6 comparing HIV-aware persons with independent groups of unaware individuals; 5 comparing seroconverters before and after learning status) demonstrated that HIV-infected individuals were likely to reduce unprotected anal or vaginal intercourse after learning their positive serostatus. After 
adjusting data to focus on partners not already infected, the analysis showed a $68 \%$ reduction in reports of unprotected anal or vaginal intercourse (Marks, G., et al. 2005). This is important because greater than $80 \%$ of HIV cases diagnosed in the United States are among individuals who report sexual exposure (CDC, 2010).

The cost-effectiveness of routine HIV screening has also been demonstrated. Recently, published papers concerning the cost-effectiveness of HIV screening concluded that even when the prevalence of HIV infection in specific populations is substantially lower than $1 \%$, screening for HIV is cost-effective relative to other established screening programs (Farnham, PG., et al., 2008). Sanders indicated that screening was also cost-effective in comparison with other commonly accepted screening programs, even when the known population prevalence of HIV was substantially lower than 1\% (Sanders, GD., et al., 2005). Immediately after infection occurs, there is a rapid rise in plasma viremia with the virus being disseminated widely in the body. During the period from initial infection to complete seroconversion (referred to as primary HIV infection), routine tests for HIV antibody are unable to detect the new infection (Fiebig, EW., et al., 2003). This high concentration of the virus has important public health implications because the HIV diagnosis could be missed, and it is a period of extreme infectiousness

(Wawer, MJ., et al. 2005).

It has been shown that the majority of seropositive patients do not present with symptoms suggestive of HIV infection. Because of their nonspecific nature, it requires a high index of suspicion to associate the symptoms of acute retroviral syndrome (ARS) with primary HIV infection. The signs and symptoms of ARS can develop within days or occur up to weeks after initial exposure. Although these can last from a few days to more than 10 weeks, symptom duration is usually less than 2 weeks (Hecht, FM., et al., 2002). Fever, fatigue, rash, and pharyngitis are the most common symptoms of ARS. Other symptoms include lymphadenopathy, myalgia, headache, arthralgia, aseptic meningitis, weight loss, depression, night sweats, gastrointestinal distress, and oral or genital ulcers. Differential diagnosis includes infectious mononucleosis, secondary syphilis, acute hepatitis A or B, roseola or other viral exanthems, and toxoplasmosis. The occurrence and severity of symptoms during primary HIV infection correlate with the rapidity of clinical and immunologic decline. The nonspecific nature of these symptoms poses a major challenge for diagnosis, and emphasizes the need to obtain an accurate history of possible HIV exposure. For example, primary HIV infection should be considered in any patient with possible exposure presenting with fever of unknown cause (Pincus, JM., et al., 2003). This was especially pronounced in episodic care settings, such as STD clinics, emergency departments and urgent care facilities. The implementation of rapid testing for routine screening can substantially reduce the number of individuals who fail to learn test results, and minimize the expenses allocated to locate persons identified as HIV infected.

\section{HIV testing with rapid technology}

With the rapid test, as with the standard (conventional) HIV test, the provider should recommend testing, provide information about the test and an explanation of the window period, and give the patient an opportunity to decline or opt out of HIV testing; guides are available online (http://www.cdc.gov/hiv/topics/research/respect-2/counseling/pdf/ RESPECT2StandardTestingCounselingProtocol.pdf). A number of US Food and Drug 
Administration (FDA)-approved rapid HIV testing products are available (http://www.cdc.gov/hiv/topics/testing/rapid/rt-comparison.htm).

Providers who will be administering the test should be trained, either by the manufacturer or the local health department, in how to use the product available at their facilities. Rapid testing is done in a single session, so a patient should be assessed for their readiness to receive results on the same day. Positive rapid test results are preliminary and must be confirmed by Western blot or direct immunofluorescence assay before a diagnosis of HIV infection is established. However, negative results are considered conclusive and follow-up is not generally required (CDC, 2004).

As previously stated, because of the same-day availability of the results, rapid testing is very suitable for patients who are unlikely to return for their results. It is also the test of choice when an immediate treatment decision needs to be made (e.g., untested woman in labor, occupational or sexual exposure). In order to reduce the mortality, morbidity, and transmission among groups most affected (http://www.cdc.gov/hiv/topics/surveillance/ resources/slides/mortality/index.htm), it is important to understand and address the reasons for late testing for HIV. Persons diagnosed with AIDS concurrently or soon after (e.g., 3 or fewer years) receiving their initial HIV test results continue to represent a significant number of missed opportunities for diagnosis and prevention. Although there has been a steady increase in the CD4 counts of infected individuals at initial presentation, a large North American data set found that the average remained below 350 cells $/ \mu \mathrm{L}$, whereas 500 cells $/ \mu \mathrm{L}$ is the lower threshold for treatment initiation recommended by the US Department of Health \& Human Services HIV treatment guidelines, as of December 2009 (http://www.aidsinfo.nih.gov/contentfiles/AdultandAdolescentGL.pdf). Data from 34 states showed that $38.3 \%$ of people who tested positive had progressed to AIDS 1 year or less after initial diagnosis of their HIV infection, and 45\% had an AIDS diagnosis within 3 years (Shouse, RL., et al., 2009).

The percentage of individuals with AIDS occurring within 3 years after diagnosis increased with age, ranging from $22.7 \%$ in adolescents (13-19 years old) to $63.2 \%$ in those older than 60 years of age. Racial disparities were also noted (42.6\% whites; $42.9 \%$ multiple/unknown race; $46.1 \%$ black/African American; $46.1 \%$ American Indian/Alaskan native; $48.4 \%$ Hispanic/Latino, and 50.4\% Asian). A greater proportion of adolescent boys/men (46.9\%) compared with adolescent girls/women (41.5\%) developed AIDS within 3 years.

Possible reasons for late testing include stigma and homophobia as well as lack of access to testing facilities. Individuals may not seek HIV testing because they do not consider themselves at risk. Also, healthcare providers may not recognize the risk factors for HIV infection or the signs and symptoms of ARS, i.e., the signs and symptoms of primary HIV infection.

\section{HIV serologic testing for men who have sex with men (MSM)}

National HIV Behavioral Surveillance (NHBS) system estimates and monitors risk behaviors and collects data from metropolitan areas. According to the 2008 NHBS report, nearly 1 in 5 MSM were infected with HIV and $44 \%$ were unaware of their serostatus (CDC, 2010), $19 \%$ of MSMs were HIV infected, with the highest rates of prevalence among blacks (28\%) followed by Hispanics $(18 \%)$ and whites $(16 \%)$. Increasing age and lower levels of income and education also were associated with higher prevalence rates. Poverty is also recognized as an important risk factor for HIV infection, and a greater proportion of MSM with no health 
insurance and those who had not visited a healthcare provider during the preceding year were unaware of their infection; $55 \%$ of those unaware of their infection were not tested during the preceding 12 months.

HIV prevalence was highest among black MSM $<30$ years of age. However, the majority of young black and Hispanic MSM in each age group were unaware of their HIV infection. Thus, available data suggest that HIV prevalence among MSM remains high; many HIV infected MSMs are unaware of their serostatus; and minority MSM are disproportionately affected by HIV. The NHBS data underscore the specific need for increased HIV testing efforts directed toward all MSM, especially minorities. It has been demonstrated that about $25 \%$ of individuals testing HIV positive and $33 \%$ of those testing negative did not return for results of standard testing (Kendrick, SR., et al., 2005).

\section{HIV serologic testing for children}

Most children were infected with HIV-1 through vertical transmission of the virus. The route of HIV-1 can occur in utero, at the time of labor and delivery, and breastfeeding. Before treatment or interventions to prevent transmission were available, the rate of MTCT of HIV-1 in the United States was approximately 25\%. And now, both clinical and laboratory-based methods for the diagnosis of HIV-1 infection in children have been developed. Laboratory-based methods include both immunologic and virological assays. Evaluations of clinical staging systems for the diagnosis of HIV-1 infection in children in sub-Saharan Africa, especially in young infants, have suggested limited sensitivity (Jones, SA., et al., 2005). Laboratory-based methods for the diagnosis of HIV-1 infection can be divided into 2 groups: immunologic and virological. The former includes (1) Detection of HIV-1 Antibodies, (2) Enzyme-Linked Immunosorbent Assays, (3) Rapid Tests which is to detection of IgG antibodies against HIV-1, (3) Semi-quantitative Antibody Assays, (4) Western Blot Assays, (5) Indirect Immunofluorescence Assays, (6) Analysis by Flow cytometry. Virological assay includes HIV-1 Culture, HIV-1 DNA Assays, HIV-1 RNA Assays and p24 Antigen Assays (Read, JS, 2007).

Rapid HIV tests provide results in min, use minimal laboratory equipment, and have been widely used especially in resource-poor settings since their introduction. However, falsenegative results have happened, especially when the tests are used in infants. The case showed above demonstrates that the rapid HIV antibody test can result in false-negative results in infants. There are at least two possible explanations for the child's negative rapid HIV-1 antibody results. First, the primary antibody production has been suppressed by the presence of maternal IgG antibodies (Karlsson, MC., et al., 1999).

Secondly, mothers living with HIV were highly immunosuppressed; therefore, the low level of maternally-derived circulating HIV-1 IgG was only detected by HIV-EIA and Western blot. While the antigen components used in the rapid assay merit further investigation, our data indicate that the HIV rapid assay test is not reliable in screening for HIV infection in infants aged $<18$ months. Due to passive transfer of maternal antibody during pregnancy, infants born to HIV-infected mothers remain antibody-positive into the second year of life, even if they are not infected. For this reason, standard HIV antibody tests cannot reliably confirm HIV infection in infants until after maternal antibodies have disappeared. Tests that can diagnose pediatric HIV infection accurately during the first year of life include HIV-PCR assays, HIV culture, and repeat p24 antigen tests (Shah, I. et al., 2006). The sensitivity and the specificity of an HIV DNA PCR at birth have been estimated to be $50 \%$ and $99 \%$, 
respectively. The sensitivity of the test improves dramatically in the first weeks of life and reaches a sensitivity of $90 \%$ or better when used in infants who are older than 1-mo of age. Two negative tests by PCR or viral culture after 3-mo of age would indicate that a child is not infected and would be more useful than screening serology. Although HIV DNA PCR and HIV RT-PCR are important tests in this clinical situation, they must be interpreted carefully. Several studies demonstrate a high sensitivity for both tests; however, specificities vary among reports. Also, HIV PCR testing should be repeated at regular, defined intervals, preferably lasting until the HIV antibody status of the infant is resolved (Sahni, AK., et al., 2005). HIV RNA amplification assays may be better at detecting HIV-infected infants than DNA PCR. In a cohort study, qualitative nucleic acid sequence-based amplification (NASBA) assay was shown to be highly specific and more sensitive than DNA PCR. NASBA results from infected children were compared with DNA PCR results from the same blood samples taken during the first 3 mo of life from HIV-infected and uninfected children. Sensitivity, specificity, and predictive values were calculated. The conclusion was that qualitative RNA assays (including RT-PCR) may be useful for diagnosing and excluding perinatal HIV infection in children after the first week of life for such purposes as initiating antiretroviral therapy and other treatment, resolving parental uncertainty, determining timing of transmission, and providing endpoints for intervention trials. Infants born to HIVinfected mothers are at great risk of becoming infected with HIV during labor and delivery. $\mathrm{HIV}$ is present in breast-milk, and the risk of transmission during breast-feeding depends on several factors including infant age, pattern of breast-feeding, breast-feeding duration, breast health, maternal viral load, and maternal immune status. HIV rapid assay may not be sensitive enough for testing HIV antibodies in infants who are less than 18-mo old. Other sensitive assays, including fourth-generation EIA as well as nucleic acid amplification-based assays should be used.

\section{HIV serologic testing for pregnant women}

Major successes have been achieved in prevention of (mother-to-child transmission) MTCT of HIV-1 in the United States; the MTCT rate has decreased to less than $2 \%$ with antiretroviral treatment of HIV-1-infected pregnant women and, for women who do not yet require treatment of their HIV-1 infection, with the use of the following efficacious interventions to prevent transmission: antiretroviral prophylaxis, cesarean section before labor and before rupture of membranes, 12 and complete avoidance of breastfeeding.

The CDC recommends that all pregnant women receive universal HIV testing as early as possible during prenatal care, with repeat testing in the third trimester in certain circumstances, such as those exhibiting signs or symptoms of infection, those with high-risk behaviors, and those living in or receiving care in areas with a high incidence or prevalence of HIV (identifies 1 HIV infection for every 1000 pregnant women tested). The screening preferably should occur at the first obstetric visit, after the patient has been informed that an HIV test will be performed unless declined (the opt-out screening model). Permission for HIV testing should be included as part of the general consent for healthcare. Clinicians should provide pregnant women with appropriate information in regard to HIV infection, risk factors, and reasons for testing, and transmission risk to ensure an informed decision about screening. Reasons for declining HIV testing should be addressed. If a woman has an unknown test history during prenatal care or undocumented serostatus at labor and delivery, she should be screened at the time of labor or immediately postpartum with a 
rapid HIV test, unless testing is declined. The majority of women with undocumented HIV testing or serostatus have few or no prenatal care visits. Rapid point-of-care testing during labor has been shown to be effective and accepted, with acceptance rates of $86 \%$ among those approached for testing during labor and delivery (Jamieson, DJ., et al., 2007).

The HIV test result of an expectant mother should be documented in her chart as well as in the medical record of her newborn. After appropriate maternal consent is given, maternal and pediatric healthcare providers should both be aware of the mother's HIV serostatus. This is necessary so that appropriate prophylaxis and testing of an HIV-exposed infant can occur, as well as proper management of any potential complications. It is important for pregnant women to know their serostatus as early as possible in the course of pregnancy to prevent transmission to infants and partners (Mofenson, L., et al., 2006; 55).

In 2005, approximately $92 \%$ of all HIV/AIDS cases in children younger than 13 years of age were due to vertical (mother-to-child) transmission. In the United States, the use of combination antiretroviral therapy during pregnancy has reduced the transmission rate from approximately $20 \%-30 \%$ to $<2 \%$. Transmission to fetuses and infants can also be prevented through antiretroviral therapy, cesarean delivery, and avoiding breast-feeding. Transmission to partners and others can be prevented by changing previous risk behaviors, such as no or inconsistent condom use and by reducing viral load through antiretroviral treatment.

All patients, including all pregnant women, should be given the option to decline HIV testing. However, the clinician should discuss the reasons for declining testing and document the decision in the medical record. Risks for HIV and reasons for testing should be thoroughly reviewed. A woman may decline HIV testing for many reasons: She may not believe that she is at risk for HIV. Fear also may be influencing her decision, whether it is fear of being HIV positive, fear of discrimination if positive, or fear of partner retribution. Often, women think that they are not at risk for HIV due to a poor understanding of HIV and its risk factors. Women may also be unaware of their partners' HIV or STD risk, which also influences HIV transmission (Witte, SS., et al., 2010).

Other reasons for refusing HIV screening include scheduling conflicts; concerns over cost; health insurance; confidentiality; and other reasons, such as having a previous negative test. Identified issues should be addressed as fully as possible by the provider, with the intent of overcoming barriers and alleviating specific concerns about screening. HIV testing should continue to be recommended at subsequent prenatal visits if this has been refused in earlier visits. However, refusing HIV testing should never affect the level or quality of prenatal care provided to the patient.

\section{References}

Adimora, AA., Schoenbach, VJ. \& Martinson, FE. (2003). Concurrent partnerships among rural African Americans with recently reported heterosexually transmitted HIV infection. Journal of Acquired Immune Deficiency Syndromes, Vol.34, No.4, pp.423-429, ISSN 1525-4135

Althoff, KN., Gange, SJ. \& Klein, MB. (2005). Late presentation for human immunodeficiency virus care in the United States and Canada. Clinical Infectious Diseases, Vol. 50, No.11, pp.1512-1520, ISSN 1058-4838

Branson, BM., Handsfield, HH. \& Lampe, MA. (2006). Centers for Disease Control and Prevention (CDC). Revised recommendations for HIV testing of adults, 
adolescents, and pregnant women in health-care settings. Recommendations and Reports: Morbidity and Mortality Weekly Report, Vol. 55, No.11, pp (RR14).1-17, ISSN 1545-8601

Campsmith, ML., Rhodes, PH.. \& Hall, HI. (2010). Undiagnosed HIV prevalence among adults and adolescents in the United States at the end of 2006. Journal of Acquired Immune Deficiency Syndromes, Vol.47, No.5, pp.619-624, ISSN 1525-4135

Centers for Disease Control and Prevention. HIV surveillance reports. Diagnoses of HIV infection and AIDS in the United States and dependent areas, 2008. Page last updated: June 14, 2010. Available from:

http://www.cdc.gov/hiv/topics/surveillance/resources/reports Accessed October 28, 2010

Centers for Disease Control and Prevention (CDC). (2004). Protocols for confirmation of reactive rapid HIV tests. Morbidity and Mortality Weekly Reports, Vol. 53, pp.221222, ISSN 1545-8601

Centers for Disease Control and Prevention (CDC). (2010). Prevalence and awareness of HIV infection among men who have sex with men -21 cities, United States, 2008. Morbidity and Mortality Weekly Reports, Vol.59, pp.1201-1207, ISSN 1545-8601

Centers for Disease Control and Prevention (CDC). (2008). Recommendations for partner services programs for HIV infection, syphilis, gonorrhea, and chlamydial infection. Recommendations and Reports: Morbidity and Mortality Weekly Report, Vol. 57(RR-9), pp.1-83, ISSN 1545-8601

Craw, JA., Gardner, LI. \& Marks, G. (2008). Brief strengths-based case management promotes entry into HIV medical care: results of the Antiretroviral Treatment Access Study-II. Journal of Acquired Immune Deficiency Syndromes, Vol. 47, No.11, pp.597-606, ISSN 1525-4135

Duffus, WA., Weis, K. \& Kettinger, L. (2009). Risk-based HIV testing in South Carolina health care settings failed to identify the majority of infected individuals. AIDS Patient Care and STDS, Vol.23, No.5, pp.339-345, ISSN 1087-7449

Farnham, PG., Hutchinson, AB. \& Sansom, SL. (2008). Comparing the costs of HIV screening strategies and technologies in health- care settings. Public Health Reports, Vol. 123 (suppl3), pp.51-62, ISSN 0033-3549

Fiebig, EW., Wright, DJ. \& Rawal, BD. (2003). Dynamics of HIV viremia and antibody seroconversion in plasma donors: implications for diagnosis and staging of primary HIV infection. AIDS, Vol.17, No.13, pp.1871-1879, ISSN 1473-5571

Hecht, FM., Busch, MP. \& Rawal, B. (2002). Use of laboratory tests and clinical symptoms for identification of primary HIV infection. AIDS, Vol.16, No.8, pp.1119-1129, ISSN 1473-5571

http://www.cdc.gov/hiv/topics/research/respect-2/counseling/pdf/ RESPECT2StandardTestingCounselingProtocol.pdf

http://www.cdc.gov/hiv/topics/testing/rapid/rt-comparison.htm http://www.cdc.gov/hiv/topics/surveillance/resources/slides/mortality/index.htm http://www.aidsinfo.nih.gov/contentfiles/AdultandAdolescentGL.pdf

Jamieson, DJ., Cohen, MH. \& Maupin, R. (2007). Rapid human immunodeficiency virus-1 testing on labor and delivery in 17 US hospitals: the MIRIAD experience. American Journal of Obstetrics and Gynecology, Vol.197 (suppl3), pp.S72-S82, ISSN 0002-9378

Jiang, X., Lu, H. \& Zhang Y. (2008). A cross-sectional study of HIV and tuberculosis coinfection cases in mainland China. Southern Medical Journal, Vol.101, No.9, pp.914-917, ISSN 0038-4348 
Jones, SA., Sherman, GG. \& Coovadia, AH. (2005). Can clinical algorithms deliver an accurate diagnosis of HIV infection in infancy? Bulletin of World Health Organization, Vol.83, No.7, pp.559-560, ISSN 0042-9686

Karlsson, MC., Wernersson, S. \& Diaz de Stahl T. (1999). Efficient IgG-mediated suppression of primary antibody responses in Fcgamma receptor-deficient mice. Proceeding of the National Academy of Science of United States of America, Vol.96, No.5, pp.2244-2249, ISSN 1091-6490

Kendrick, SR., Kroc, KA. \& Withum, D. (2005). Outcomes of offering rapid point-of-care HIV testing in a sexually transmitted disease clinic. Journal of Acquired Immune Deficiency Syndromes, Vol.38, No.2, pp.142-146, ISSN 1525-4135

Marks, G., Crepaz, N. \& Senterfitt, JW. (2005). Meta-analysis of high-risk sexual behavior in persons aware and unaware they are infected with HIV in the United States: implications for HIV prevention programs. Journal of Acquired Immune Deficiency Syndromes, Vol.39, No.4, pp.446-453, ISSN 1525-4135

Mofenson, L., Taylor, AW. \& Rogers, M. (2006). Achievements in public health: reduction in perinatal transmission of HIV infection -United States, 1985-2005. Morbidity and Mortality Weekly Report, Vol.55, pp.592-597, ISSN 0149-2195

Pincus, JM., Crosby, SS. \& Losina, E. Acute human immunodeficiency virus infection in patients presenting to an urban urgent care center. Clinical Infectious Diseases, 2003; 37:1699-1704

Read, JS. (2007). Diagnosis of HIV-1 infection in children younger than 18 months in the United States. Pediatrics, Vol.120, No.6, pp.1547-1562, ISSN 0031-4005

Sahni, AK., Gupta, RM. \& Jena, J. (2005). Early detection of HIV-1 in infants by PCR. Indian Journal of Pathology and Microbiology, Vol.48, No.1, pp.49-52, ISSN 0974-5130

Sanders, GD., Bayoumi, AM. \& Sundaram, V. (2005). Cost-effectiveness of screening for HIV in the era of highly active antiretroviral therapy. The New England Journal of Medicine, Vol.352, No.6, pp.570-585, ISSN 1533-4406

Shah, I. (2006). Efficacy of HIV PCR techniques to diagnose HIV in infants born to HIV infected mothers-an Indian perspective. Journal of Association of Physicians of India, Vol.54, pp.197-199, ISSN 0004-5772

Shouse, RL., Kajese, T. \& Hall, HI. (2009). Late HIV testing-34 states, 1996-2005. Morbidity and Mortality Weekly Report, Vol.58, pp.661-665, ISSN 1545-8601

Taylor, Z., Nolan, CM. \& Blumberg, HM. (2005). American Thoracic Society, Centers for Disease Control and Prevention, Infectious Diseases Society of America. Controlling tuberculosis in the United States: recommendations from the American Thoracic Society, CDC, and the Infectious Diseases Society of America. Recommendations and Reports: Morbidity and Mortality Weekly Report, Vol.54 (RR12), pp.1-81, ISSN 1545-8601

Wawer, MJ., Gray, RH. \& Sewankambo, NK. (2005). Rates of HIV-1 transmission per coital act, by stage of HIV-1 infection, in Rakai, Uganda. Journal of Infectious Diseases, Vol.191, No.9, pp.1403-1409, ISSN 1528-8366

Witte, SS, El-Bassel, N. \& Gilbert, L. (2010). Lack of awareness of partner STD risk among heterosexual couples. Perspectives on Sexual and Reproductive Health, Vol.42, No.1, pp.49-55, ISSN 1931-2393

Zhang, YZ., Wang, J. \& Wilson, GJ. (2008). Negative results of a rapid antibody test for HIV in a 16-month-old infant with AIDS. Annals of Clinical and Laboratory Science, Vol.38, No.3, pp.293-295, ISSN 1550-8080 


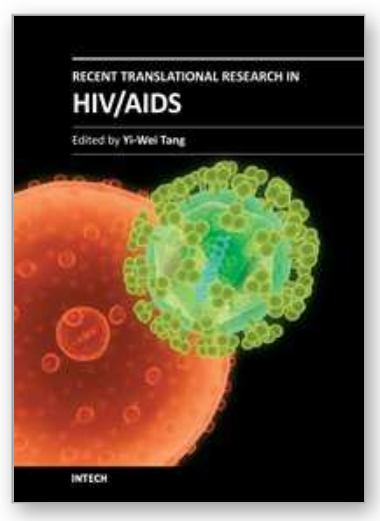

\author{
Recent Translational Research in HIV/AIDS \\ Edited by Prof. Yi-Wei Tang
}

ISBN 978-953-307-719-2

Hard cover, 564 pages

Publisher InTech

Published online 02, November, 2011

Published in print edition November, 2011

The collective efforts of HIV/AIDS research scientists from over 16 countries in the world are included in the book. This 27-chapter Open Access book well covers HIV/AIDS translational researches on pathogenesis, diagnosis, treatment, prevention, and also those beyond conventional fields. These are by no means inclusive, but they do offer a good foundation for the development of clinical patient care. The translational model forms the basis for progressing HIV/AIDS clinical research. When linked to the care of the patients, translational researches should result in a direct benefit for HIV/AIDS patients.

\title{
How to reference
}

In order to correctly reference this scholarly work, feel free to copy and paste the following:

Jiasheng Shao, Yunzhi Zhang, Yi-Wei Tang and Hongzhou Lu (2011). Pearls and Pitfalls of HIV-1 Serologic Laboratory Testing, Recent Translational Research in HIV/AIDS, Prof. Yi-Wei Tang (Ed.), ISBN: 978-953-307719-2, InTech, Available from: http://www.intechopen.com/books/recent-translational-research-in-hivaids/pearls-and-pitfalls-of-hiv-1-serologic-laboratory-testing1

\section{INTECH}

open science | open minds

\section{InTech Europe}

University Campus STeP Ri

Slavka Krautzeka 83/A

51000 Rijeka, Croatia

Phone: +385 (51) 770447

Fax: +385 (51) 686166

www.intechopen.com

\section{InTech China}

Unit 405, Office Block, Hotel Equatorial Shanghai

No.65, Yan An Road (West), Shanghai, 200040, China

中国上海市延安西路 65 号上海国际贵都大饭店办公楼 405 单元

Phone: +86-21-62489820

Fax: +86-21-62489821 
(C) 2011 The Author(s). Licensee IntechOpen. This is an open access article distributed under the terms of the Creative Commons Attribution 3.0 License, which permits unrestricted use, distribution, and reproduction in any medium, provided the original work is properly cited. 